\title{
İmar Uygulamalarında Farklı Dağıtım Metotlarının Karşılaştırılması
}

\author{
Ramazan GÜNGÖR ${ }^{1 *}$, Şaban İNAM ${ }^{2}$ \\ ${ }^{1}$ Manisa Celal Bayar Üniversitesi, Demirci Meslek Yüksekokulu, Coğrafi Bilgi Sistemleri Programı, Manisa \\ (ramazan.gungor@cbu.edu.tr) ORCID ID 0000-0002-6338-8554 \\ ${ }^{2}$ Konya Teknik Üniversitesi, Mühendislik ve Doğa Bilimleri Fakültesi, Harita Mühendisliği Bölümü, Konya \\ (sinam@selcuk.edu.tr) ORCID ID 0000-0002-8570-3076
}

\begin{abstract}
$\ddot{O ̈ z}$
Ülkemizde arsa düzenlemesi çalışmaları, düzenlemeye alınan her parselden yüzölçümü oranında kesinti esasına dayanmaktadır. Ancak, yapılan pek çok çalışma bu uygulama şeklinin doğruluğunu ve güvenilirliğini test etmektedir. Özellikle 3194 sayılı İmar Kanununun 18. maddesi uygulamalarında kadastro parselleri ile bu parsellere tahsis edilen imar parsellerinin değer ilişkisinin tutarsızlık göstermesi haksız kazanç ortaya çıkarmaktadır. Bu nedenle yapılan çalışmada, arsa düzenlemeleri kapsamında düzenleme öncesi kadastro parsellerine farklı dağıtım metotları ile tahsis edilen imar parsellerinin alan-değer ilişkisinin incelenmesi amaçlanmıştır. Bu doğrultuda, ilgili kamu kurumlarından ve özel ofislerden grafik ve vektör veri temini sağlanmış ve analiz edilmiştir. Uygulamada, taşınmaz değerlerinin belirlenmesinde değer ile doğrudan ilişkili faktörler ve rayiç değerler kullanılmıştır. Elde edilen bu değerler ile imar uygulaması yapılmış ve dağıtım aşamasında incelenmiştir. Önerilen uygulama şeklinin geçerliliğinin kanıtlanması için mevcut uygulanan metot ile karşılaştırmalar yapılmışıır. Yapılan analizler ve yorumlamalar sonucunda yürürlükteki imar uygulamasının adalet ve eşitlik olgularından uzak olduğu anlaşılmıştır. Taşınmazların parsel bazında birim değerlerinin belirlenmesi ve bu doğrultuda arazi ve arsa düzenlemesi (AAD) uygulamalarının yapılması, sorunların büyük oranda ortadan kalkmasına yardımcı olacaktır.
\end{abstract}

Anahtar Kelimeler: arsa düzenlemesi, dă̆ıtım, değerleme, eşdeğerlilik,

\section{Comparison of Different Distribution Methods in Readjustment Applications}

\begin{abstract}
In our country, the land arrangement works are based on the deduction of the land area from each parcel, which is regulated. However, many studies have tested the accuracy and reliability of this application. Especially 3194/18. Clause applications, the discrepancy between the cadastral parcels and the value relationship of the parcels allocated to these parcels proves unfair gains. For these reasons, it is aimed to investigate the relationship between the area and value of the parcels allocated to the cadastral parcels with different reallocation methods. In this respect, graphics and vector data were obtained from the relevant public institutions and private offices and analyzed. In application, the factors directly related to the value and the fair values were used to determine the immovable values. A readjustment application was made with these values and examined during the allotment phase. Comparisons have been made with the method currently applied to prove the validity of the proposed method of administration. As a result of the analyzes and interpretations made, it is understood that the current readjustment application is far from the facts of justice and equality. Determination of unit values of real properties on the basis of parcels and in this direction, land and land arrangement applications, it will help to eliminate the problems to a great extent.
\end{abstract}

Keywords: Land regulation, Distributing, Valuation, Equivalence,

\footnotetext{
* Sorumlu Yazar
} 


\section{GíRiş}

Sürdürülebilir bir kentleşme modelinin kurulması; doğru yorumlanan, planlanan ve uygulanan arsa ve arazi üretiminin desteği ile sağlanabilir (Bovkır ve Aydınoğlu, 2018). Bu doğrultuda, imar uygulamalarından beklenen sadece planlı yapılaşmayı temin etmek olmamalıdır. $\mathrm{O}$ bölgede yaşayan halkın ihtiyaçları doğrultusunda ulaşım, sosyal, kültürel, sağlık, çalışma vb. hizmetler sağlanmalıdır (Ünel, vd., 2017). Bu bir kazanım ölçütüdür. Zira bu hizmetlerin sağlanması için oluşturulan kaynak, taşınmaz sahipleri tarafından karşılanmaktadır (Koçak, 2009). Düzenlemeye tabi tutulan taşınmazlarda yapılan uygulamadan kaynaklı plana ve mevzuata uygun yapılanma şartları sağlanmaktadır. $\mathrm{Bu}$ durum, taşınmazlarda değer artışına neden olacaktır. Ancak 3194 sayılı İmar Kanununda açıkça belirtilen yerlerin sağlanması için bir alan kesintisi uygulanır (Aksoy, 2013). Düzenleme ortaklık payı (DOP) ile her parselden düzenlemeye giren alan oranında kesinti yapılmaktadır. $\mathrm{Bu}$ kesinti, imar planlarının uygulanması ile parsel bazında ortaya çıkan değer artışı miktarına karşı1lı gelmektedir. Ancak, bu kesinti miktarı her parselde aynı oranda olmasına karşın düzenleme sahasında oluşan değer artışını eşit miktarda karşılayamamaktadır (Gökce, 2014). Oysaki mevcut kadastro parselinin yapis1 imar planları ile arsa ve arazi düzenlemesi kapsamında değişime uğrayacaktır. Düzenlemeye alınan parsellerin sadece geometrik durumları değil, hukuki durumlarına ait ekonomik faktörlerde de iyileştirme meydana gelecektir. İmar uygulamaları ile taşınmazlarda sadece sınır ve mülkiyet değişikliği yapılmamaktadır. $\mathrm{Bu}$ nedenle düzenlemeye giren her parsel özelinde ortaya çıkan artış, eşit oranda tüm sahaya dağıtılamaz. Mevcut uygulanan yöntemde imar parsellerine dağıtımı gerçekleşen kadastro parsellerinin kesinti oranı düşüldükten sonraki alanı sağlayıp sağlamadığı kontrol edilmektedir. Ancak düzenleme öncesi parsellerin değeri ile tahsis edilen imar parsellerinin değeri belirlenmeli ve aynı değerde yer sağlanıp sağlanmadığına dikkat edilmelidir. Aksi halde yapilan uygulamalarda adaletsiz durumlar ortaya çıkmaya devam edecektir. Örneğin, bir düzenleme sahasında yer alan iki farklı adanın imar planı özellikleri incelendiğinde, farklı yapılaşma koşulları ortaya çıkabilir. $\mathrm{Bu}$ adalarda yer alan parsellerin plan sonucu oluşan değer artışından aynı oranda etkilendiğinden söz edilemez (Yalpır ve Ekiz, 2017). Bu durum imar uygulamalarında haksız kazanç ortaya çıkarmaktadır (Yılmaz ve Demir, 2017). Özellikle kentsel alan yönetim faaliyetleri kapsamında arazi kullanımında meydana gelen değişiklikler, idari düzenlemeler, kadastro planlamaları gibi görevler arazi özelliklerine dikkat edilmesi gereken görevlerdir (Zeng ve Cleon, 2018). $\mathrm{Bu}$ durum dikkate alınmaz ise özellikle tarım arazisi olarak kullanilan alanlarda arazi kullanım kararları ile ilgili var olan tartışmalar sürecek, kırsal karakterin korunması yönünde oluşan alg1 toprak politikalarının sürekli eleştirilmesine neden olacaktır (Arendt, 2014; Hawkins, 2014; Mohamed, 2017).

Ülkemizde uygulanan arsa düzenlemesi çalışmalarında dağıtım işlemi, parsellerin yüzölçümü oranında yapılan kesinti sonrası kalan miktar üzerinden yapılmaktadır. Ancak düzenlemeye giren parsel değerleri birbirinden farklı olduğu gibi düzenleme sonrası oluşan imar parsel değerleri de birbirinden farklıdır. Düzenlemeye alınan kadastro parsellerinin imar planlarıyla ortaya çıkan değer artışı miktarından eșit oranda faydalanması için dağıtım ișlemlerinin 'oran' yerine 'değer' esas alınarak yapılmas1 gerekmektedir (Y1ldiz ve vd., 2008). Ülkemizde uygulanmaya çalışılan arsa ve arazi düzenlemelerinin tek eksiği dağıtım aşamasında değer eşitliğini esas alan yöntemin eksikliğidir (Omar, 2013). Mevcut uygulanan yönteme göre özellikle parsellerin yeni baştan dağıtımı aşamasında, nesnel değerleme yöntemlerinin kullanılmaması pek çok itiraza neden olmaktadır. Ortaya çıkan sorunlar göz önüne alınarak arazi ve arsa düzenlemesi (AAD) uygulamaları yeniden dağıtım aşamasında düzenleme öncesi (DÖ) ve düzenleme sonrası (DS) parsel birim 
değerleri esas alınmalıdır (Yomralığlu, 1992).

\section{MATERYAL ve YÖNTEM}

\subsection{Uygulama Metodolojisi}

Yapılan uygulamada seçilen pilot saha özelinde 3194 say1l İmar Kanunun 18. Maddesine göre düzenleme sınırı içerisinde yer alan kadastro parsellerine bir arsa düzenlemesi yapılmıştır. Bu kapsamda tahsise göre arsa üretimi gerçekleşmiştir. $\mathrm{Bu}$ yöntemin amacı yönetmelikte belirtilen standartları sağlayan en küçük boyutta imar parselini sağlayan kadastro parsellerine müstakil parsel tahsisi yapmaktır (İspir, 2006). Bu doğrultuda 18. Madde esaslarına göre yani alan esaslı yöntem ile imar parsellerinin dağıtımı gerçekleştirilmiştir. Nominal değerleme yönteminde ise imar uygulamasina katılan parseller ve uygulama sonrası oluşan imar parselleri için değere etki eden faktörler ve bu faktörlere ilişkin ağırlık katsayıları kullanılarak birim ve toplam değerler hesaplanmıştır. Ayrıca düzenleme sahasında yer alan tüm parsel rayiç değerleri temin edilmiştir (URL_1). Hesaplanan ve temin edilen bu değerler doğrultusunda dağıtım işlemi değer bazlı olarak tekrar yapılmıştır. Son olarak alan ve değer esaslı yapılan dağıtım işlemleri karşılaştırılmıştır. Dağıtım aşamasında ortaya çıkan farklılıklar, denkleştirme miktarları ve değer artışı doğrultusunda yapılacak kesinti miktarları karşılaştırılarak yorumlanmıştır.

\section{2. Çalışma Sahası}

Çalışma bölgesi olarak Manisa ili, Demirci İlçesi sınırları içerisinde, belediye imar planı sınırlarında yer alan bir saha seçilmiştir. Uygulama sahası, imar planında 'gelişim sahası' olarak gösterilmektedir. Düzenleme kapsamında değerlendirilen 21 adet kadastro parselinin toplam yüzölçümü $208.977,83 \mathrm{~m}^{2}$ dir. Kadastro paftası ile 1: 1000 ölçekli uygulama imar planının ilişkilendirilmesi sonucu çizilen düzenleme sınırı alanı ise 127.731,52 $\mathrm{m}^{2}$ olarak belirlenmiştir. Düzenlemeye giren kadastro parselleri alanı ise 108.932,42 $\mathrm{m}^{2}$ olarak ölçülmüştür. Düzenlemeye giren parsellerin mülkiyet bilgileri incelendiğinde 14 adet parselin 1/1 oranında hisseli olduğu, diğer parsellerin farklı oranlarda hisselere sahip olduğu görülmüştür. Ayrıca, Planlı Alanlar İmar Yönetmeliğinde belirtilen esaslar çerçevesinde oluşturulan parselasyon planlarında 308 adet imar parseli üretilmiştir. Uygulama sahası içerisinde planda gösterilen ve kamu ortaklık payı oranında hisse oluşturulacak 1 adet sosyal tesis de yer almaktadır.

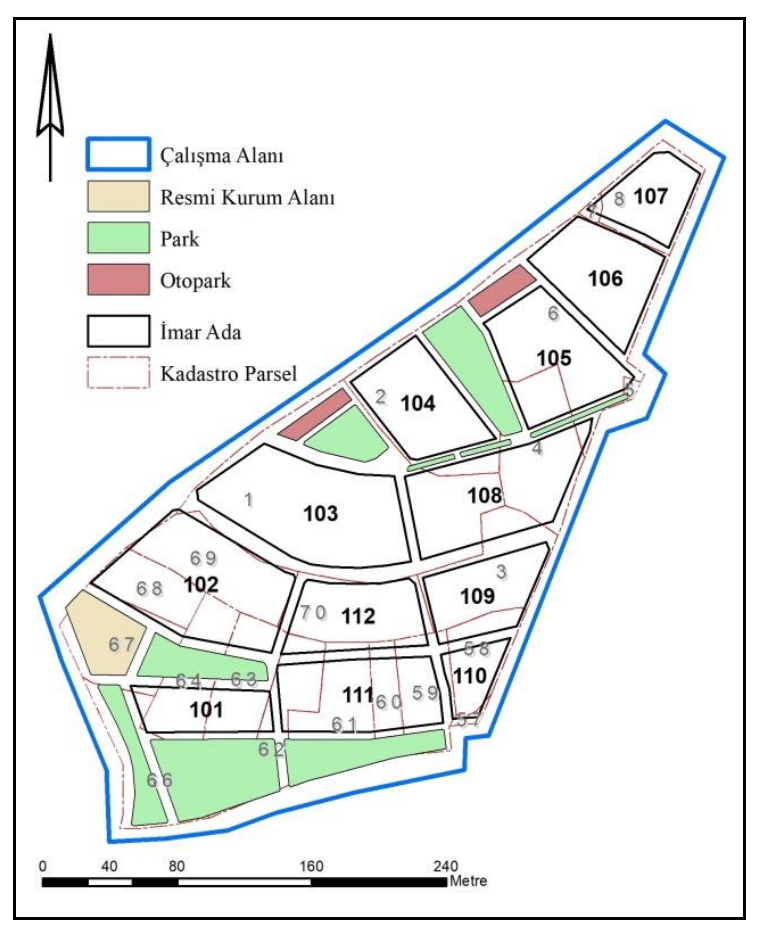

Şekil 1. Çalışma Sahası Durumu

\subsection{Nominal Değerleme Yöntemi}

Global düzeyde yapılan pek çok taşınmaz değerleme uygulamasında rayiç değerler esas alınmaktadır. Fakat değerleme işlemi sırasında esas alınan faktörlerin birçoğu ülkenin içerisinde bulunduğu ekonomik yapı itibariyle değişiklik gösterebilir (Frizzell,1979). Aynı zamanda değerleme çalışması yapılan sahanın büyük olması veya taşınmaz sayısının oldukça fazla olması değerleme işlemlerini zora sokmaktadır. $\mathrm{Bu}$ doğrultuda özellikle değerleme uygulaması yapılacak büyük sahalarda taşınmazın rayiç değeri esas alınabileceği gibi bir puanlama işlemi neticesinde elde edilecek parametrik değerler de söz konusudur. $\mathrm{Bu}$ yöntemde taşınmaz değerini etkileyen değer faktörleri tespiti yapılarak bu faktörlere ilişkin puanlama yoluna gidilir. Elde edilen bu puan 
değerleri, değeri etkileyen katsayılar ile çarpılarak konu taşınmazın değeri belirlenir (Nişanc1, 2005). Düzenleme öncesi ve düzenleme sonrası parsellerin nominal değerlerinin, yani değere etki eden faktörlere göre değer hesabının yapılmasında aşağıdaki matematiksel model kullanılır (Yomralıoğlu, 1992).

$V=$ Parsel Alanı $* \sum_{\mathrm{i}}^{\mathrm{n}} \sum_{\mathrm{j}}^{\mathrm{k}}\left(\mathrm{Vij}_{\mathrm{j}} * \mathrm{~W}_{\mathrm{j}}\right)$

$(\mathrm{i}=1,2, \ldots \ldots, \mathrm{n}),(\mathrm{j}=1,2, \ldots \ldots, \mathrm{n}), \mathrm{V}$ : Parsel toplam değeri, $\mathrm{v}$ : Faktör Puanı, w : Faktör ağırlığı, $\mathrm{k}$ : Toplam faktör sayısı, $\mathrm{n}$ : Parsel say1s1

\section{BULGULAR}

\subsection{Düzenleme Öncesi ve Düzenleme Sonrası Parsel Değerleri}

AAD çalışmalarında dikkat edilmesi gereken en kritik nokta, dağıtım aşamasının bir modele oturtulmasıdır. Dağıtım aşaması ile ilgili modellemede "eşdeğerlilik" ilkesi benimsenecekse, bu yöntem bir değerleme sistemi ile bütünleştirilmelidir (Köktürk ve Köktürk, 2009). Değerleme işlemi sırasında taşınmazı ilgilendiren değer faktörleri seçilirken objektif unsurlar göz önünde bulundurulmalıdır (Swango, 2016). Özellikle değerleme aşamasında taşınmaz ile ilgili fiziksel, sosyal, ekonomik ve hukuki durumlar ön planda tutulmalıdır (Droj ve Droj, 2015).Taşınmaz değerini etkileyen değişkenler ve bu değişkenlere ait ağırlık katsayıları kullanılarak hem düzenleme öncesi mevcut kadastro parsel değerleri hem de düzenleme sonrası oluşan imar parseli değerleri hesaplanmıştır. Değer hesaplamalarında kullanılan faktörler, hem katılım parselleri hem de dağıtım parselleri için kullanılmıştır. Değerleme aşamasında, hesaplama işlemi (Yomralığlu, 1992)' nun belirlediği yöntem ve değişkenlere ait (İnam, 1993)'in belirlediği ağırlık katsayıları esas alınarak yapılmıştır. Değeri etkileyen değişkenlerin önem sırası ve değere katkısı literatürde anket çalışmaları ile açıklanmıştır (Yomralıoğlu, 1992; Bender vd., 2000; Kryvobokov, 2005; Nişanc1, 2005; Yalpır, 2007; Çakır ve Sesli, 2013).
Tablo 1. Değer Faktörü Katsayıları (İnam, 1993).

\begin{tabular}{|l|c|}
\hline Faktör & Katsayı \\
\hline Topoğrafya Durumu & $65,30 / 1930$ \\
\hline Yola Çıkış & $77,60 / 1930$ \\
\hline Parselin Geometrik Durumu & $80,60 / 1930$ \\
\hline $\begin{array}{l}\text { Kamu Hizmetlerinin Olup } \\
\text { Olmadığı }\end{array}$ & $88,00 / 1930$ \\
\hline Çevre Faktörü & $81,40 / 1930$ \\
\hline Anayola Olan Uzaklık & $60,00 / 1930$ \\
\hline Parsel Toprağının Cinsi & $86,20 / 1930$ \\
\hline Zeminde Var Olan Kaynaklar & $77,10 / 1930$ \\
\hline Parselin İmar Durumu & $75,10 / 1930$ \\
\hline Parsel Hisse Sayısı & $62,50 / 1930$ \\
\hline Bulunduğu İmar Ada İçi Konumu & $75,40 / 1930$ \\
\hline Parselin Verimli Kullanı Alanı & $78,20 / 1930$ \\
\hline Parsel Bakı/Cephesi & $70,30 / 1930$ \\
\hline Şehir Merkezine Uzaklık & $69,00 / 1930$ \\
\hline $\begin{array}{l}\text { Şehrin Suç Oranı Yüksek } \\
\text { Merkezlerine Olan Uzaklık }\end{array}$ & $76,50 / 1930$ \\
\hline Ĕğitim Merkezlerine Uzaklık & $79,30 / 1930$ \\
\hline $\begin{array}{l}\text { Alış-Veriş Merkezlerine Olan } \\
\text { Mesafesi }\end{array}$ & $78,30 / 1930$ \\
\hline Sağlık Servislerine Olan Uzaklık & $82,60 / 1930$ \\
\hline Yeşil Alana Olan Mesafesi & $68,40 / 1930$ \\
\hline İbadet Merkezlerine Uzaklık & $61,20 / 1930$ \\
\hline Tren Garına Uzaklık & $56,30 / 1930$ \\
\hline İtfaiyeye Olan Uzaklık & $61,40 / 1930$ \\
\hline $\begin{array}{l}\text { Güvenlik Merkezlerine Olan } \\
\text { Uzaklık }\end{array}$ & $61,40 / 1930$ \\
\hline $\begin{array}{l}\text { İzin Verilen Yapı Yüksekliği Veya } \\
\text { Kat Sayısı }\end{array}$ & $42,10 / 1930$ \\
\hline Gürültü Yüksekliği(Db) & $74,30 / 1930$ \\
\hline
\end{tabular}

Katılım parselleri için; parselin imar durumu, parsel hisse sayısı, parsel toprağının cinsi, zeminde var olan kaynaklar, anayola olan uzaklık, parselin geometrik durumu, kamu hizmetlerinin olup olmadığı, yola çıkış, topoğrafya durumu, çevre faktörü gibi değişkenlere dikkat edilmiştir.

Dağıtım parselleri için; gürültü yüksekliği(db), izin verilen yap1 yüksekliği veya kat sayısı, topoğrafya durumu, yeşil alana olan mesafesi, alış-veriş merkezlerine olan mesafesi, parsel toprağının cinsi, anayola olan mesafesi, parselin geometrik durumu, parsel baki/cephesi, parselin verimli kullanım alanı, bulunduğu imar ada içi konumu, tren garına, ibadet merkezlerine, eğitim merkezlerine, şehrin suç oranı yüksek 
merkezlerine, şehir merkezine, güvenlik merkezlerine olan mesafeleri değişkenlerine dikkat edilmiştir. Ayrıca, aynı taşınmazların kadastro ve imar parseli nominal değerleri ve rayiç değerleri hem birim hem de toplam olarak iki ayrı sınıfta hesaplanmıştır (Tablo 2, Tablo 3).

Tablo 2. Farklı Metotlar İle Hesaplanan Kadastral Parsel Değerleri

\begin{tabular}{|c|c|c|c|}
\hline \multicolumn{2}{|c|}{ Kadastro Parselleri } & Ada/Parsel & Değer \\
\hline \multirow{4}{*}{ 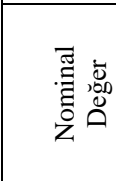 } & Min. Birim Değ. & $362 / 5$ & 13,62 \\
\hline & Max.Birim Değ. & $362 / 62$ & 28,01 \\
\hline & Min. Değer & $362 / 5$ & 2120,26 \\
\hline & Max. Değer & $362 / 1$ & 417807,58 \\
\hline \multirow{4}{*}{ 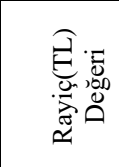 } & Min. Birim Değ. & $362 / 5$ & 14,00 \\
\hline & Max.Birim Değ. & $362 / 57$ & 24,00 \\
\hline & Min. Değer & $362 / 5$ & 2177,37 \\
\hline & Max. Değer & $362 / 1$ & 403358,30 \\
\hline
\end{tabular}

Tablo 3. Farklı metotlar ile hesaplanan imar parsel değerleri

\begin{tabular}{|c|c|c|c|}
\hline \multicolumn{2}{|c|}{ İmar Parselleri } & Ada/Parsel & Değer \\
\hline \multirow{4}{*}{ 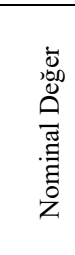 } & $\begin{array}{l}\text { Min. Birim } \\
\text { Değ. }\end{array}$ & $107 / 15$ & 31,00 \\
\hline & $\begin{array}{l}\text { Max.Birim } \\
\text { Değ. }\end{array}$ & $101 / 1$ & 39,65 \\
\hline & Min. Değer & $107 / 9$ & 3368,18 \\
\hline & Max. Değer & $108 / 21$ & 22236,36 \\
\hline \multirow{4}{*}{ 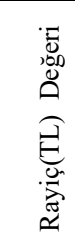 } & $\begin{array}{l}\text { Min. Birim } \\
\text { Değ. }\end{array}$ & $\begin{array}{l}106 \text { ve } 107 \text { ada } \\
\text { parselleri }\end{array}$ & 85,00 \\
\hline & $\begin{array}{l}\text { Max.Birim } \\
\text { Değ. }\end{array}$ & $\begin{array}{c}109,110 \text { ve } 111 \\
\text { ada parselleri }\end{array}$ & 105,00 \\
\hline & Min. Değer & $107 / 9$ & 9024,54 \\
\hline & Max. Değer & $108 / 21$ & 62932,50 \\
\hline
\end{tabular}

Kadastro ve imar parsel değerlerinin kendi içinde değişkenlik göstermesinin nedeni, her parsel özelinde farklılık gösteren değer faktörleri, ağırlık katsayıları ve parsellerin konumları ile açıklanabilir.

\subsection{Alan ve Değer Bazlı Dağıtım Uygulamalarının Kıyaslanması}

Alan tahsisine dayanarak uygulanan imar parseli üretimi (parselasyon) çalışmalarının amaçlarından bir tanesi de, düzenleme öncesi $1 / 1$ oranında hisseye sahip mülkiyet oranının korunmas1 ve ayn1, tam mülkiyet hissesine sahip imar parseli dağıtımı yapılmasıdır. Yapılan uygulama kapsamında asgari ölçüde imar parseli boyutlarını sağlayan kadastro parsellerine karşıllk tam mülkiyette imar parseli tahsisi yapılmıştır. Ancak bu boyutların sağlanamadığı durumlarda hisseli parsel tahsisi yapılmıştır.

İmar uygulaması çalışmalarında değer eşitliğini esas alan modelin uygulanabilmesi için DÖ kadastro parselleri ve DS imar parselleri değerinin bir değerleme yaklaşımı ile tayini gerekmektedir (İspir, 2006). Bu amaçla, çalışma sahasında öncelikle tahsise göre parsel üretimi gerçekleştirilmiştir. Dağıtım aşamasında düzenlemeye katılım gösteren parsellere eşdeğer yerlerden imar parseli verilmiştir. Ancak katılım parselleri yüzölçümlerin oldukça büyük olması ve hissesiz/müstakil mülkiyette parseller olmas1 düzenleme sonrası hisseli parsel sayısının artmasına sebebiyet vermiştir. Tahsise göre yapılan ve alan kesintisi esas alınarak uygulanan yöntemde daha az hisseli parsel üretilmiştir. $\mathrm{Bu}$ durumun oluşmasının temel sebebi ise kadastro parsellerinin kendi değerinde alanlara dağıtımının yapılmasıdır.

Eş oranlı kesinti uygulamasına göre kadastro parsellerine tahsisi yapilan imar parseli alanları farklılık göstermektedir (Tablo 4). 3194 say11 İmar Kanununun 18. madde uygulamasında, düzenlemeye giren her parselden eşit oranda kesinti miktarı amaçladığından, parsellerin yüzölçümleri oranında $\% 37$ düzenleme ortaklık payı kesintisi yapılmış ve kalan alan üzerinden dağıtım işlemi gerçekleştirilmiştir. Ayrıca düzenleme sahası sınırları içerisinde yer alan resmi kurum hizmet alanı kapsamında her parsel $\% 2$ oranında bu alana hisselendirilmiştir. Taşınmaz değerleri esas alınarak yapılan uygulama metodunda ise, önce nominal değerlere göre sonrasında taşınmazların rayiç değerlerine göre dağıtım parselleri tahsisi yapılmıştır. Mevcut/yürürlükteki arsa ve arazi düzenlemesi şekli ile iki farklı değerleme yaklaşımı kullanılarak yapılan uygulamalar arasında özellikle dağıtım aşamasında farklılıklar belirlenmiştir. Düzenleme kapsamında 'alan' esas alınarak yapılan uygulama şeklinde düzenlemeye katılım gösteren her parselden aynı düzenleme 
ortaklık payı oranında alan kesintisi yapıldı ğı; fakat değer eşitliğini esas alan uygulamalarda bu oranın parsel özelinde farklılık gösterdiği saptanmıştır. Bu farklılığın oluşma nedeni ise kadastro parselleri ile bu parsellere tahsis edilen imar parselleri değerlerinin denkleştirilmesidir. Düzenlemeye alınan bir parsel ile dağıtımı yapılan parsel değerlerinin farklılaşması, bu parselde yapılacak kesinti oranını doğrudan etkilemektedir. Yani, bir kadastro parseline kendi değerinden daha fazla değerde alan tahsisi yapılır ise bu oran artacaktır. Tam tersi durum da söz konusudur. Yapılan analizler sonucunda bazı kadastro parselleri ile tahsis edilen imar parseli değerleri birbirine yakınken, bazı parsel değerleri de oldukça farklıdır. Eş oran esasına göre tahsis edilen alan ile nominal değerleme yöntemi yardımı ile hesaplanan değerler kullanılarak tahsis edilen alan arasındaki fark $877,49 \mathrm{~m}^{2}$ dir. Yine eş oran esasına göre tahsis edilen alan ile taşınmazların rayiç değerleri üzerinden tahsis edilen alan miktarı arasında ki fark 917,05 $\mathrm{m}^{2}$ dir. Yani, her iki karşılaştırma şeklinde de alan bazlı uygulamada daha az alan tahsisi yapılmıştır. Değer eşitliğini esas alan iki yöntemin tahsis miktarları karşılaştırıldığında, bu miktar 39,56 $\mathrm{m}^{2}$ olarak hesaplanmıştır. Bu sonuçtan da anlaşılıyor ki, imar uygulamaları dağıtım aşaması değer eşitliğini esas alan yöntemlere göre uygulanmalıdır. Örneğin; düzenleme sınırı içerisinde yer alan 362 ada-1 numaralı kadastro parseline "eş oran" esasına göre yapılan dağıtımda düzenleme ortaklık payı düşüldükten sonra $12.640,69 \mathrm{~m}^{2}$ alan tahsis edilmiştir. Ancak bu alan, nominal yönteme göre yapılan uygulamada $12.830,31 \mathrm{~m}^{2}$, rayiç değerlere göre yapılan uygulamada 12.489,37 $\mathrm{m}^{2}$ olmuştur. Yani 362 ada- 1 numaralı kadastro parseline nominal değer (değeri etkileyen faktörler) uygulamasında $189,62 \mathrm{~m}^{2}$ fazla alan tahsisi yapılırken, rayiç değerlere göre yapılan uygulamada $151,32 \mathrm{~m}^{2}$ eksik alan tahsisi yapılmıştır. $\mathrm{Bu}$ farklığın oluşmasının nedeni ise, dağıtım aşamasında verilen imar parseli değerlerinin farklllık göstermesidir. Yine aynı parsel üzerine yapılacak inşaat taban alanı incelendiğinde alan farklılıkları söz konusu olacaktır.
Düzenlemeye giren kadastro parsellerine düzenleme sonrasında, değerine eşit imar parseli tahsisi yapılabilmesi için DOP gibi her parselden eşit oranda kesinti esasına dayanan kavramdan uzaklaşılması gerekir. Çünkü yapılan uygulamada her kadastro parseli, dağıtımı yapılan imar parseli değeri özelinde bir kesintiye uğramıştır. $\mathrm{Bu}$ nedenle, her parselde ortaya çıkan kesinti miktarı farklılık göstermektedir. Nominal yöntem ile yapılan uygulamada minimum kesinti oran1 62 numaral1 parselde 0.14, maksimum kesinti oran1 5 numaralı parselde 0.60 oranında olmuştur. $\mathrm{Bu}$ oranların değişiklik gösterme nedeni, değer olarak eşitsizliklerin oluşmasıdır. Ayrıca taşınmazların rayiç değerlerine göre yapılan uygulamada minimum kesinti oranı 66 numaralı kadastro parselinde 0.28 iken, maksimum kesinti 6 numaralı parselde 0.56 olmuştur. Yapılan hesaplamalar neticesinde kadastro parselleri ile bu parsellere tahsis edilen imar parselleri değerleri arasındaki fark arttıkça veya azaldıkça yapılacak kesinti oranı da aynı oranda artacak veya azalacaktır.

Yürürlükteki mevzuat gereğince yapılan imar uygulaması yönteminde, düzenlemeye giren kadastro parsellerinden yapılan eş oranlı alan kesintisi, düzenleme sonrasında oluşan değer artışını her parsel için aynı oranda karşılamamaktadır. Düzenleme sonrasında üretilen ve kadastro parsellerine tahsis edilen imar parseli alanı, sahip olduğu değere göre dağıtılmalıdır. Bu nedenle, 'eş oran' esasına göre yapılan dağıtım, taşınmaz mülkiyeti açısından adaletli bir yöntem değildir. Yapılan çalışma da göstermiştir ki, dağıtım aşamasında uygulanacak faktörler "değer" faktörleri olmalıdır. Dağıtımda esas alınacak değer ise kadastro parselleri birim değeridir. 
Tablo 4. Tahsise göre yapılan dağıtım ile değere göre yapılan dağıtımda uygulanan kesinti miktarları

\begin{tabular}{|c|c|c|c|c|c|c|c|c|c|c|c|c|}
\hline & & & & & & & & & & & & \\
\hline$\frac{\pi}{4}$ & 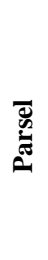 & 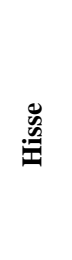 & 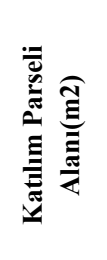 & 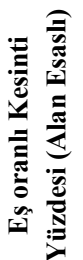 & 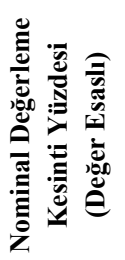 & 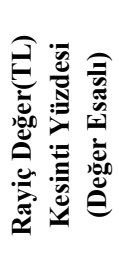 & 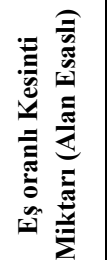 & 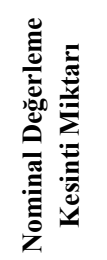 & 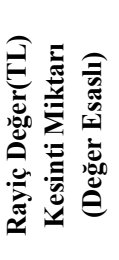 & 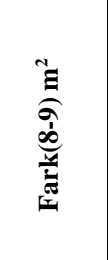 & 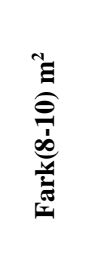 & 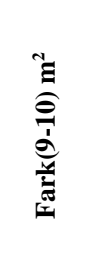 \\
\hline 1 & 2 & 3 & 4 & 5 & 6 & 7 & 8 & 9 & 10 & 11 & 12 & 13 \\
\hline 362 & 61 & 1 & 4852,91 & 0,37 & 0,33 & 0,29 & 1772,15 & 1582,23 & 1418,33 & 189,91 & 353,82 & 163,91 \\
\hline & 62 & 1 & 5028,86 & 0,37 & 0,14 & 0,29 & 1836,40 & 680,90 & 1469,75 & 1155,50 & 366,65 & $-788,85$ \\
\hline & & $1 / 4$ & 1018,73 & 0,37 & 0,55 & 0,29 & 372,01 & 562,00 & 297,74 & $\begin{array}{l}-189,99 \\
\end{array}$ & 74,27 & 264,26 \\
\hline & 63 & $1 / 4$ & 1018,73 & 0,37 & 0,51 & 0,29 & 372,01 & 524,62 & 297,74 & $-152,61$ & 74,27 & 226,89 \\
\hline & (5) & $1 / 4$ & 1018,73 & 0,37 & 0,50 & 0,29 & 372,01 & 514,45 & 297,74 & $-142,44$ & 74,27 & 216,71 \\
\hline & & $1 / 4$ & 1018,73 & 0,37 & 0,50 & 0,29 & 372,01 & 504,43 & 297,74 & $-132,41$ & 74,27 & 206,69 \\
\hline & & $1 / 3$ & 1443,41 & 0,37 & 0,39 & 0,29 & 527,09 & 565,24 & 421,86 & $-38,14$ & 105,24 & 143,38 \\
\hline & & $1 / 3$ & 1443,41 & 0,37 & 0,43 & 0,29 & 527,09 & 618,76 & 421,86 & $-91,67$ & 105,24 & 196,90 \\
\hline & 64 & $1 / 12$ & 360,85 & 0,37 & 0,39 & 0,29 & 131,77 & 141,83 & 105,46 & $-10,06$ & 26,31 & 36,37 \\
\hline & 64 & $1 / 12$ & 360,85 & 0,37 & 0,39 & 0,29 & 131,77 & 140,48 & 105,46 & $-8,71$ & 26,31 & 35,02 \\
\hline & & $1 / 12$ & 360,85 & 0,37 & 0,39 & 0,29 & 131,77 & 139,30 & 105,46 & $-7,52$ & 26,31 & 33,83 \\
\hline & & $1 / 12$ & 360,85 & 0,37 & 0,39 & 0,29 & 131,77 & 138,93 & 105,46 & $-7,16$ & 26,31 & 33,47 \\
\hline
\end{tabular}

\subsection{Denkleştirme Bedellerinin Belirlenmesi}

Eş oranlılık esasına göre yapılan imar uygulaması yaklaşımı ile iki farklı değerleme (Nominal ve Rayiç değer) yaklaşımı kullanılarak yapılan kentsel alan düzenleme çalışmasında katılım parsellerine tahsisi yapılan imar parselleri değerleri ve tahsis sonucu ortaya çıan değer farklılıkları incelenmiştir. Yapılan hesaplamalar neticesinde, tahsis edilen imar parselleri değerine göre adaletsiz bir dağıtım uygulaması yapıldığı kanısına varılmıştır. Düzenleme sonras1 oluşan imar parseli değerlerinde düzenleme öncesi parsel değerlerine göre artış söz konusu olmuştur. $\mathrm{Bu}$ durum, düzenlemeden dolayı sağlanan hizmet alanları, parsel biçimi vb. nedenlerle açıklanabilir. $\mathrm{Bu}$ değer artışı, kuramsal bir değer artışı olup mülkiyet hakkının korunması amaciyla düzenleme öncesi parsel katılım değerine denkleştirilmelidir. Bu amaçla, hem nominal yöntem için hem de rayiç değerler için bir " $p$ " katsayısı hesaplanmıştır. Değeri etkileyen değişkenlere göre ortaya çıan kuramsal nominal değer artışı $\mathrm{p}_{\mathrm{N}}=\% 105(1,0477)$, Rayiç değerler kullanılarak ortaya çıkan kuramsal değer artışı $\mathrm{p}_{\mathrm{T}}=\% 3310 \quad(0,3096)$ oranında belirlenmiştir. Hesaplanan bu katsayılar, kendi uygulama yöntemi özelinde katılım parseli değeri ile çarpılarak kuramsal paylar hesaplanmıştır. Kadastro parsellerinin tahsis edildiği imar parseli tahsis değerleri ile kuramsal pay değerleri karşılaştırıldığında, kadastro parsellerine eksik veya fazla değerde alan tahsisi sağlandığı görülmüştür. $\mathrm{Bu}$ nedenle, dağıtımdan dolayı ortaya çıkan değer farklılaşmasının düzenlemeyi yapan kurum veya yaptıran malik tarafından karşılanması için denkleştirme bedelleri ödenmelidir (Tablo $5)$. 
Tablo 5. Tahsis edilen parseller için TL denkleştirme bedelleri

\begin{tabular}{|c|c|c|c|c|c|c|c|c|c|c|c|c|}
\hline \multicolumn{5}{|c|}{ KATILIM(KADASTRO) } & \multicolumn{2}{|c|}{ KURAMSAL } & \multicolumn{6}{|c|}{ TAHSIS (IMAR) } \\
\hline 1 & 2 & 3 & 4 & $5=3 * 4$ & $6=5 * q N$ & $7=6-5$ & 8 & 9 & 10 & $11=9 * 10$ & $12=11-6$ & 13 \\
\hline$\stackrel{y}{z}$ & 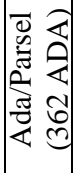 & $\begin{array}{l}\text { ฏ્ } \\
\text { స్ँ }\end{array}$ & : & 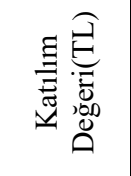 & 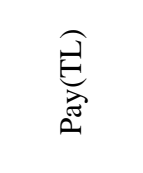 & 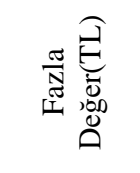 & 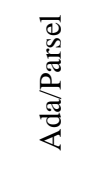 & 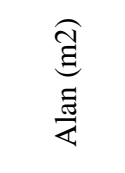 & 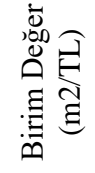 & 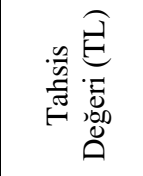 & 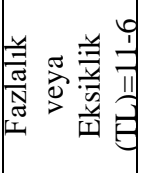 & 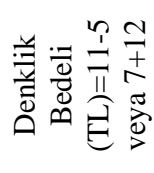 \\
\hline $\mathrm{M}$ & 6 & 3531,94 & 14,00 & 49447,22 & 153105,77 & 103658,55 & $105 / 17$ & 99,71 & 100,00 & 9970,90 & 66091,77 & 169750,31 \\
\hline & & & & & & & $105 / 18$ & 262,26 & 100,00 & 26225,50 & & $(169750,31)$ \\
\hline & & & & & & & $105 / 19$ & 254,02 & 100,00 & \begin{tabular}{|l|l}
25401,90 \\
\end{tabular} & & \\
\hline & & & & & & & $105 / 20$ & 245,99 & 100,00 & 24599,10 & & \\
\hline & & & & & & & $105 / 21$ & 238,14 & 100,00 & 23814,30 & & \\
\hline & & & & & & & $105 / 22$ & 229,93 & 100,00 & 22992,70 & & \\
\hline & & & & & & & $105 / 23$ & 221,90 & 100,00 & 22189,80 & & \\
\hline & & & & & & & $105 / 24$ & 213,87 & 100,00 & 21386,90 & & \\
\hline & & & & & & & $105 / 25$ & 302,92 & 100,00 & 30292,20 & & \\
\hline & & & & & & & $106 / 1$ & 144,99 & 85,00 & 12324,24 & & \\
\hline & & & & & & & & Toplam= & & 219197,54 & & \\
\hline
\end{tabular}

\section{SONUÇ ve TARTIŞMA}

$\mathrm{Bu}$ çalışma, Manisa ili Demirci ilçesinde seçilen bir sahada arsa düzenlemesinin farklı metotlar ile gerçekleştirilmesini ve dağıtım ilişkilerinin incelenmesi amacıyla yapılmıştır. Alan esasina göre uygulanan yöntemde her parselden \%37,68 oranında kesinti yapilırken nominal değerleme yaklaşımında bu oran her parsel özelinde farklı olmakla birlikte ortalama $\% 37,64$, rayiç değerlere göre yapılan uygulamada ortalama \%35,02 dir. Alan ve rayiç değer esasına göre yapılan yöntem ile dağıtımı yapılan parsellerden 265 adet müstakil parsel tahsisi sağlanırken nominal değerleme yaklaşımında bu sayı 262 olarak belirlenmiştir. Dağıtım işlemi sırasında alan esaslı yöntem ve nominal değerleme yaklaşımına göre yapılan karşılaştırmada toplam 104.287,13 ND denkleştirme bedeli hesaplanırken, alan esaslı ve rayiç değere göre yapılan dağıtımın karşılaştırmasında 4.534.820,67 TL denkleştirme bedeli hesaplanmıştır. Ayrıca düzenleme ortaklık pay1 kapsamında değerlendirilecek genel hizmet alanları için toplam 39779,12 $\mathrm{m}^{2}$ alan kullanılmıştır. Kesinti yapılan bu alanın düzenlemeye giren tüm parsellere rayiç değer olarak dağılımı $-46322,76 \mathrm{TL}$ dir. Bu fark nominal değerleme yaklaşımına göre incelendiğinde -10594,92 ND dir. Yani DOP, rayiç değere ve nominal değere göre yapılan uygulamalarda hesaplanan değerlerde mal sahiplerini kârlı çıkarmıştır. Arazi ve arsa düzenlemesi çalışmalarında değer eşitliğini esas alan modelin kullanılması, düzenlemeden dolayı oluşan özel çıkarların birbirine eşitlenmesini sağlayacaktır. Özellikle dağıtım aşamasında ortaya çıkan istisnai durumlar, tahsise göre alan uygulamalarının sağlıklı bir şekilde yürütülmesini güçleștirmektedir. Çünkü uygulama sürecinde parsel bazında ortaya çıkan değişiklikler, mülkiyetin içeriğini ve sinırlarını belirlemektedir. Diğer bir ifadeyle, hukuki değișiklikler malik bilgilerinde değil, nesnel mülkiyet hakkında yapılmaktadır. Böylelikle düzenleme sınırı içerisinde kalan saha veya saha içerisinde yer alan bir katılım parseli amacina uygun olarak hazırlanmış bir plana göre biçimlendirilmektedir. Planda öngörülen yapısal kullanım için katılım parselleri maliklerinin, dağıtım kütlesindeki hakları veya payları düzenlemeden önce belirlenmelidir. $\mathrm{Bu}$ durumun sağlanması ise düzenleme öncesinde parsellerin birbirlerine karşı olan değer oranlarının veya farklılıklarının ortaya koyulması ile oluşacaktır.

Kentsel alan düzenleme çalışmalarında değer eşitliğini esas alan modelin uygulanabilmesi için bu çalışmada kullanılacak değerleme yaklaşımlarının net bir şekilde ortaya koyulması ve yasal düzenlemeler ile kayıt altına alınması gerekmektedir. Seçilen pilot saha üzerinde yapılan çalışmadan da anlaşılmıştır ki, oran eşitliğini esas alan uygulama şeklinin dağıtım aşaması birçok problemi içerisinde barındırmaktadır. Uygulamanın dağıtım aşamasında hisseli parsel sayısının değer esas alınan yöntemlerde arttığ1 gözlenmiştir. Ancak bu durum değer olarak eşit tahsisin sağlandığı anlamına gelmemektedir. Çünkü eşit oranlı dağıtım 
işlemi sırasında değer bir ölçüt olarak kabul edilmemektedir. $\mathrm{Bu}$ aşamada taşınmaz mülkiyeti ile ilgili teknik, hukuki ve fiili olarak doğru bir yöntem uygulamas1 sağlanamamaktadır. Arsa ve arazi düzenlemesi çalışmalarında taşınmaz değerini doğrudan veya dolaylı olarak etkileyen faktörler belirlenmeli bu doğrultuda uygulamalar yapılmalıdır. $\mathrm{Bu}$ nedenle, mevcut uygulanan sistemin en baştan değiştirilmesi, yerine uygulanma kabiliyeti olan 'değer' esaslı bir sistemin inşası gerekmektedir.

\section{KAYNAKÇA}

Aksoy, M., (2013). İmar Mevzuatı Ve Danıştay Kararları Çerçevesinde Arazi Ve Arsa Düzenlemesi, İstanbul Kültür Üniversitesi Fen Bilimleri Enstitüsü, Yüksek Lisans Tezi, İstanbul.

Arendt, Randall G., (2014). Clarifying the Conservation Subdivision Design Approach. Planetizen. (Erişim Tarihi:04.05.2018), http://www.planetizen.com/node/67619.

Bender, A., Din, A., Hoesli, M., Brocher, S., (2000). Environmental preferences of homeowners, further evidence using the AHP method. Journal of Property Investment \& Finance, 18(4), 445-55.

Bovkir, R., Aydınoğlu, A., C., (2018). Providing land value information from geographic data infrastructure by using fuzzy logic analysis approach. Land Use Policy, 78, 46-60. https://doi.org/10.1016/j.landusepol.2018.06 .040

Bünyan Ü., F., Yalpir, Ş., Gülnar, B., (2017). Preference Changes Depending on Age Groups of Criteria Affecting the Real Estate Value. International Journal of Engineering and Geosciences, 2(2), 41-51. https://doi.org/10.26833/ijeg.297271

Çakır, P., Sesli, A. F., (2013). Arsa Vasıflı Taşınmazların Değerine Etki Eden Faktörlerin $\mathrm{Ve} \mathrm{Bu}$ Faktörlerin Önem Siralarının Belirlenmesi Harita Teknolojileri Elektronik Dergisi, 5(3), 1-16.

Droj, L., Droj, G., (2015). Usage Of Location Analysis Software In The Evaluation Of Com- Mercial Real Estate Properties. Journal of Procedia Econ. Finance,32,826832.

Frizzell, R., (1979). The Valuation of Rural Property, Lincoln College, New Zeland.

Gökce, D., Salalı V., (2014). Kentsel Dönüşümde "Eşdeğerlik" İlkesinin Önemi, SDÜ Fen Bilimleri Enstitüsü Dergisi, 18(1), 55-65.
Hawkins, Christopher V., (2014). Landscape Conservation Through Residential Subdivision Bylaws: Explanations for Local Adoption. Landscape and Urban Planning,121,141-48.

İspir, G., (2006). İmar Uygulamalarında Değer Farklı1ıkları Ve Dağıtım İlişkileri, Karadeniz Teknik Üniversitesi Fen Bilimleri Enstitüsü, Yüksek Lisans Tezi, Trabzon.

İnam, Ş., (1993). Kentsel Alan Düzenlemelerinde Alternatif Bir Uygulama Yöntemi, Selçuk Üniversitesi Fen Bilimleri Enstitüsü, Doktora Semineri, Konya.

Koçak, H., (2009). İmar Uygulamasinda Düzenleme Ortaklik Payı, https://www.hkmo.org.tr/resimler/ekler/213 a8959a9a9658_ek.pdf (Erişim Tarihi:22.03.2019).

Köktürk, E., Köktürk, E., (2009). Eşdeğerlik İlkesine Dayalı Arsa Düzenlemesinde Taşınmaz Değerlerinin Belirlenmesi. HKMO Jeodezi, Jeinformasyan ve Arazi Yönetimi Dergisi, 2(101): 10-17.

Kryvobokov, M., (2005). Estimating the weights of location attributes with the Analytic Hierarchy Process in Donetsk. Nordic Journal of Surveying and Real Estate Research, 2(2), 5-29.

Mohamed, R., (2017). Why Might Developers Be Reluctant to Build Conservation Subdivisions? Insights from Spatial Regression Analysis. Urban Affairs Review, 107808741770999.doi:10.1177/1078087417 709998

Nişanc1, R., (2005). CBS ile Nominal Değerleme Yöntemine Dayalı Piksel Tabanlı Kentsel Taşınmaz Değer Haritalarının Üretilmesi. Karadeniz Teknik Üniversitesi, Fen Bilimleri Enstitüsü, Doktora Tezi Trabzon,61 s.

Omar, A.,(2013). Kentsel Alan Düzenlemelerinde Alternatif Uygulama Yöntemleri ve Sonuçlarin Analizi, Selçuk Üniversitesi, Fen Bilimleri Entitüsü, Yüksek Lisans Tezi, Konya. $58 \mathrm{~s}$.

Swango, D., (2016). Land uses and value resources on corridors, land use regulation and retail leases. The Appraisal Journal, 3(1), 151-162.

URL_1:https://webportal.demircibld.gov.tr/web /guest/5 (Erişim Tarihi:04.05.2019).

Yalpır, Ş., (2007). Bulanık Mantık Metodolojisi İle Taşınmaz Değerleme Modelinin Geliştirilmesi Ve Uygulaması: Konya Örneği. Selçuk Üniversitesi, Fen Bilimleri Enstitüsü, Doktora Tezi, Konya, $20 \mathrm{~s}$.

Yalpır, Ş., Ekiz, M.,(2017). Eşdeğerlilik Esaslı Arazi ve Arsa Düzenlemesinde Analitik Hiyerarşi Prosesinin Kullanımı. Ömer 
Halisdemir Üniversitesi Mühendislik Bilimleri Dergisi, 6(1),59-75.

Yıldız, F., Özkan, G., Yalpır, Ş., Yıldırım, H., Gökmen, A., Öztaş, M., (2008). Alan Düzenleme Ana Uygulama Esaslarının Belirlenmesinde Değer Eşitliğini Esas Alan Modellerin Uygulanması Üzerine Bir Araştırma. HKMO Jeodezi, Jeinformasyan ve Arazi Yönetimi Dergisi, 1(99):2, 5-14.

Yılmaz, A.,Demir, H.,(2017). İmar Uygulamasında (3194/18) Değer Esas1, Maliyet Karşılama ve Değer Kazanımı. TMMOB Harita ve Kadastro Mühendisleri Odasl, 16. Türkiye Harita Bilimsel ve Teknik Kurultayl, Ankara.

Yomralığlu, T., (1992). Arsa ve Arazi Düzenlemesi için Yeni Bir Uygulama Şekli, www.hkmo.org.tr/resimler/ekler/2M5C_824 0cb8235e9c49_ek.pdf? (Erişim Tarihi:13.02.2019).

Zeng, Z., Cleon, C. B., (2018). Factors affecting the adoption of a land information system: An empirical analysis in Liberia. Land Use Policy,73(1037),353-362.

https://doi.org/10.1016/j.landusepol.2017.12 .034 